\title{
Old Age and Creativity
}

\author{
Stanley Deser
}

$\mathrm{I}$ HAVE RECENTLY REREAD Kenneth Clark's Rede Lecture, delivered at Cambridge in 1970, on artists and writers as they grow old. ${ }^{1}$ He drew some surprising conclusions: the writers were less likely to carry on, whereas some of the greatest artists, Michelangelo, Titian, Rembrandt van Rijn, J. M. W. Turner, Paul Cézanne, Claude Monet, Henri Matisse, and in our day, Pablo Picasso and Jasper Johns, became, if anything, more productive and liberated from convention as they went into old age, despite the physical effort involved. Clark did not really give the whys of the old-in both senses-masters' endurance as against the poets' falling off.

This led me to consider my own field: physics, mostly theoretical. Of course, Clark was an eminent art critic and historian, while I am only a geriatric working stiff, whose life as a researcher gives me a technical appreciation of my field. Physics has its historians, but if there are physics critics in the same sense as art critics, then I am, perhaps wrongly, unaware of them.

Physics's greatest giants either died young, as did James Clerk Maxwell at age 48, or stopped meaningful work well before they died, as in the cases of Isaac Newton, Albert Einstein, Niels Bohr, Werner Heisenberg, Paul Dirac, and Max Born, or changed fields, like Erwin Schrödinger. Mathematicians, a different breed entirely, had Leonhard Euler and Carl Friedrich Gauss who kept going until a very old age, for their times-76 and 77despite starting very early, as mathematicians seem to do. This is not a universal trend: in the twentieth century, David Hilbert at 81 and André Weil at 92 are the only exemplars that come to mind. Physics seems to have no very old top-tier contributors. I write this from the inside, as a more-than-ninety-year-old theoretician still able to take note of those both above and around me. I can vouch for my own evolution, and that of many peers. Longevity has become common these days; there are lots of octo- and nonagenarians, but those past, say, seventy or so are apt to be winding down. Because the field relies so much on mutual support for its evolution, its present, mostly quiescent, state makes things harder for us all. Much output is focused on a few old favorites such as black holes and strings, but those are the snows of yesteryear. A few major figures are less bound by anti-speculative rules, but so far to no major effect.

Why is this-why are we more like writers than painters? There is no obvious parallel, although one may perhaps attribute it to the sort of creative resources required. I can see in my own case that, as I age, it becomes much harder to calculate, a necessary-but far from sufficient-activity for applying any new ideas. Creative ideas still come, albeit at a slower rate and lower level. Be that as it may, the oldage effect seems to be age-old, even in the field's highly productive periods. Max Planck, Arnold Sommerfeld, and to some extent Hendrik Lorentz, who were old giants in such eras, did not significantly contribute to them. On the whole, those giants who did not die young went into self-imposed retirement: Newton to head the Royal Mint, Bohr to agitate for world peace, Dirac simply to quit, and Heisenberg to administer and go into disastrous speculative research, as if to prove the point. On the experimental side, Ernest Rutherford died at 66 , so his superhuman vitality could not be tested. Enrico Fermi and Wolfgang Pauli also died young. Einstein lived on and kept on calculating, but it was an empty exercise, as I think he himself knew.

The next tier is by no means a negligible force either, but it seems to have been the same story on the whole. A few-including Hans Bethe, who lived to 99-were such formidable calculators that they could persevere, if at a lesser level. The other example of a bulldozer was Ludwig Boltzmann, but he died of mental illness at 62. Then there are sad cases of careers cut short, each different-Pascual Jordan, Lev Landau, Richard Feynman, Julian Schwinger, Oskar Klein and Princeton's three W's: John Archibald Wheeler, Arthur Wightman and Eugene Wigner. In my own cohort, Murray Gell-Mann and his student Ken Wilson each moved to greener pastures long before they died, leaving the one shining exception, Steven Weinberg, who just died at 88 , still producing textbooks as well as physics.

The obvious answer is the brain's gradual deterioration, but the artists also needed theirs to function-if perhaps in a different way than physicists. In that case, what about Euler and Gauss, in an era when physics and math were 
not yet separated? I suppose there are always a few exceptions, but why only those two so long ago and so few since? There are a lot of skewing effects, to be sure, but the trend is still clear, if hardly explained.

Stanley Deser is emeritus Ancell Professor of Physics at Brandeis University and a Senior Research Associate in Physics at the California Institute of Technology.

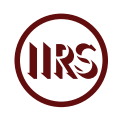

1. Kenneth Clark, The Artist Grows Old: The Rede Lecture 1970 (Cambridge: Cambridge University Press, 1972).

DOI: $10.37282 / 991819.22 .9$ 